International Journal of

Environmental Research and

Public Health

ISSN 1660-4601

www.mdpi.com/journal/ijerph

Article

\title{
Differences of Urinary Arsenic Metabolites and Methylation Capacity between Individuals with and without Skin Lesions in Inner Mongolia, Northern China
}

\author{
Qiang Zhang ${ }^{1}$, Yongfang $\mathrm{Li}^{2}$, Juan Liu ${ }^{3}$, Da Wang ${ }^{2}$, Quanmei Zheng ${ }^{2}$ and Guifan Sun ${ }^{2, *}$ \\ 1 Department of Occupational and Environmental Health, School of Public Health, \\ Tianjin Medical University, No. 22, Qi Xiang Tai Road, Heping District, Tianjin 300070, China; \\ E-Mail: qiangzhang@tijmu.edu.cn \\ 2 Environment and Non-Communicable Disease Research Center, School of Public Health, \\ China Medical University, No. 92, Bei Er Road, Heping District, Shenyang 110001, China; \\ E-Mails: liyongfang_17@163.com (Y.L.); 472594283@163.com (D.W.); \\ qmzheng@mail.cmu.edu.cn (Q.Z.) \\ 3 Library of Tianjin Medical University, Tianjin Medical University, No. 22, Qi Xiang Tai Road, \\ Heping District, Tianjin 300070, China; E-Mail: libliujuan@tijmu.edu.cn \\ * Author to whom correspondence should be addressed; E-Mail: sungf@ mail.cmu.edu.cn; \\ Tel.: +86-24-326-1744; Fax: +86-24-2326-1744.
}

Received: 28 April 2014; in revised form: 25 June 2014 / Accepted: 9 July 2014 /

Published: 18 July 2014

\begin{abstract}
Incomplete arsenic (As) methylation has been considered a risk factor of As-related diseases. This study aimed to examine the difference of urinary As metabolites and the methylation capacity between subjects with and without skin lesions. Urinary inorganic arsenic (iAs), monomethylarsonic acid (MMA), and dimethylarsinic acid (DMA) were analyzed. The percentage of each As species (iAs\%, MMA\%, and DMA\%), the primary methylation index (PMI) and secondary methylation index (SMI) were calculated. The results showed that subjects with skin lesions have higher levels of urinary iAs (99.08 vs. $70.63 \mu \mathrm{g} / \mathrm{g} \mathrm{Cr}, p=0.006$ ) and MMA (69.34 vs. $42.85 \mu \mathrm{g} / \mathrm{g} \mathrm{Cr}, p=0.016$ ) than subjects without skin lesions after adjustment for several confounders. Significant differences of urianry MMA\% (15.49 vs. 12.11, $p=0.036)$ and SMI (0.74 vs. 0.81, $p=0.025$ ) were found between the two groups. The findings of the present study suggest that subjects with skin lesions may have a lower As methylation capacity than subjects without skin lesions.
\end{abstract}


Keywords: arsenic; groundwater; skin lesion; methylation capacity; metabolism

\section{Introduction}

Arsenic (As) exists ubiquitously in the environment. Globally, an estimated 130 million people expose to As from drinking water [1]. Groundwater As contamination in China remains a serious public health problem. A recent study reported that 19.6 million people in China could be exposed to As-contaminated drinking water (As level above $10 \mu \mathrm{g} / \mathrm{L}$ ) [2]. It is well established that chronic As exposure is associated with a variety of health hazards in a dose-response pattern, including skin lesions $[3,4]$. However, recent studies indicated that the development of As-related diseases is not only determined by the levels of As exposure, but also by the variation of As metabolism [5,6,7].

In drinking water, inorganic As (iAs) is usually found in the form of arsenate (As ${ }^{\mathrm{V}}$ ) and arsenite $\left(\mathrm{As}{ }^{\mathrm{III}}\right)$. The ingested iAs is mainly metabolized in the human liver and two pathways concerning As metabolism are proposed. The generally accepted classical metabolic pathway consists of a series of reduction and oxidative methylation, which is catalyzed by reductases and methyltransferases [8]. In the reactions, the pentavalent oxidative As species is formed before the respective trivalent As species as fellows: iAs $^{\mathrm{V}} \rightarrow \mathrm{iAs}^{\mathrm{III}} \rightarrow$ monomethylarsonic acid $\left(\mathrm{MMA}^{\mathrm{V}}\right) \rightarrow$ monomethylarsonous acid $\left(\mathrm{MMA}^{\mathrm{III}}\right) \rightarrow$ dimethylarsinic acid $\left(\mathrm{DMA}^{\mathrm{V}}\right) \rightarrow$ dimethylarsinous acid $\left(\mathrm{DMA}^{\mathrm{III}}\right)$. The newly proposed pathway suggests that trivalent As species are formed before pentavalent species and $\mathrm{MMA}^{\mathrm{V}}$ and $\mathrm{DMA}^{\mathrm{V}}$ are proposed as the end products during As metabolism [9]. Although there is difference, both pathways indicate that methylation plays a key role in understanding As biotransformation. In general, trivalent arsenicals are more toxic than their pentavalent analogs [10]. Recent studies indicated that MMA $^{\mathrm{III}}$ is the most toxic intermediate during As metabolism [11]. Arsenic methylation process is incomplete and iAs along with MMA and DMA are excreted in human urine. Therefore, the percentages of urinary As metabolites (iAs\%, MMA\%, DMA\%) can give a reflection of the As methylation efficiency in human body. In addition, primary methylation index (PMI) and secondary methylation index (SMI) are usually used as indicators for evaluating the methylation capacity of individuals.

Higher MMA\% value and lower DMA\% and SMI values suggest an incomplete methylation of As in human body, which probably indicates higher $\mathrm{MMA}^{\mathrm{III}}$ at cellular level. Epidemiologic studies have shown that reduced As methylation capacity is associated with As-related diseases including skin lesions, skin cancer, bladder cancer and hypertension $[12,13,14,15]$. The variability in As methylation capacity can be partially explained by genetic polymorphisms $[6,16,17]$. However, a number of studies showed that demographic characteristics and environmental factors such as gender, age, body mass index (BMI), personal lifestyle, as well as dietary factors and nutritional status can influence the As metabolism $[18,19,20]$. Therefore, it is better to evaluate the association between As methylation capacity and human diseases with the consideration of potential confounders that might be influential to As methylation. Thus, our study aimed to investigate the possible difference in urinary As metabolites and the methylation capacity between subjects with and without skin lesions by adjustment for potential factors in a highly exposed population of rural China. 


\section{Materials and Methods}

\subsection{Study Area and Subjects}

This study was conducted in two villages of Huhhot Basin, which is situated to the northern bank of the Yellow River and to the southern edge of Da Qing Mountains. This region was reported as an endemic arsenism area, where the groundwater is known to be contaminated with naturally geogenic As [21].

According to the Declaration of Helsinki Ethical Principles for Medical Research Involving Human Subjects, a cross-sectional study approved by Ethics Committee of China Medical University was carried out in the two villages. In brief, adult inhabitants (above 18 years old) of Han nationality were included in the study based on the following requirements: (1) residents who lived in one of the two villages for at least 10 years and (2) who had not ingested seafood in the past one week. Pregnant women were excluded. A total of 302 subjects participated in this study. Informed consent was read and signed by all of the participants at the beginning of the survey. A questionnaire was used to obtain information of each individual including sex, age, type of work, socioeconomic conditions, lifestyle of smoking and drinking, dietary habits, and medical history. Medical examination, including measurement of standing height and body weight, was performed by board certified medical doctor according to the standard methods.

\subsection{Skin Examination}

Physical examinations, including a full skin exam, were performed by board certified medical doctor according to the Diagnosis Standards on Endemic Arsenicosis of China (WS/T211-2001, Ministry of Health 2001). In brief, subjects who had obvious skin abnormalities, including hyperpigmentation or depigmentation on trunk and hyperkeratosis on the palms and soles were diagnosed as arsenicosis [22].

\subsection{Urine Sample Collection and Arsenic Analysis}

Spot urine sample was obtained from each participant into a polypropylene container, kept on ice, immediately transferred to the Center for Disease Control in Huhhot, and kept at $-20{ }^{\circ} \mathrm{C}$ at a refrigerator. These samples were then shipped on dry ice to the Laboratory of Arsenic Analysis at China Medical University (Shenyang, China), stored at $-20{ }^{\circ} \mathrm{C}$ and finally measured for As species within 3 months.

Determination of urine As metabolites, iAs, MMA, DMA, and trimethylarsonic acid (TMA), was performed by hydride generation-cold trap-atomic absorption spectrophotometer (HG-cold trap-AAS) procedure. This method is reliably and has been commonly used to determine As species in water and biological samples [23,24]. Procedure for detailed quantitation of As species can be found elsewhere [25].The detection limit of this method for those As species is $1 \mathrm{ng}$. A standard As reference material, SRM 2670 (National Institute of Standards and Technology [NIST], Gaithersburg, MD, USA), containing $480 \pm 100 \mu \mathrm{g} / \mathrm{L}$ As was used as a quality control to check the validity of urinary As species measurement. The value determined by our system was $474 \pm 20 \mu \mathrm{g} / \mathrm{L}$. The reliability of four As species was evaluated by the analytical recovery rates of added As species. Spiking urine samples with $10 \mu \mathrm{g} / \mathrm{L}$ of iAs, MMA, DMA and TMA resulted in recoveries of 81\%-92\%, 88\%-98\%, 89\%-103\% and $80 \%-95 \%$, respectively. Individual urinary creatinine $(\mathrm{Cr})$ was measured by Jaffe reaction as 
described previously. The final reported urinary As metabolites concentration was adjusted by $\mathrm{Cr}$ to remove the influence of urine dilution in spot urine sample.

\subsection{Statistical Analysis}

As TMA was not detected in any sample, total As (tAs) concentration in urine was reported by summing up the concentrations of iAs, MMA and DMA. The proportions of urinary As metabolites were defined as iAs/tAs $\times 100 \%(\mathrm{iAs} \%), \mathrm{MMA} / \mathrm{tAs} \times 100 \%(\mathrm{MMA} \%)$ and DMA/tAs $\times 100 \%(\mathrm{DMA} \%)$. Two methylation indices, including PMI [(MMA + DMA)/tAs] and SMI [DMA/(MMA + DMA)], were used to evaluate As methylation capacity. BMI was calculated as weight in kilograms divided by the square of height in meters for all participants. Data with a skewed distribution were logarithmically transformed before statistical tests. The differences of urianry As species and methylation indices between subgroups of sex, age, BMI, smoking and drinking were analyzed by Student's t-test. The differences of urinary As metabolites and the methylation capacity between subjects with and without skin lesions were compared by Analysis of Covariance (ANCOVA), which is an analysis procedure for looking at group effects on a continuous outcome when some other explanatory variable also has an effect on the outcome. Multivariate-adjusted means were estimated by general linear models with fixed factors and covariates in different models, including sex in Model 1, sex, age and BMI in Model 2, and sex, age, BMI, smoking and drinking in Model 3. These analyses were conducted using the Statistical Package for the Social Sciences (SPSS, version 16.0, SPSS Inc., Chicago, IL, USA). The $p$-value for statistical significance was defined as $p<0.05$.

\section{Results}

\subsection{Baseline Characteristics of the Study Population}

The detailed demographic characteristics of the study population have been described in our previous study [25]. In brief, 302 subjects, including 120 males and 182 females, were involved in this study. The proportions of smoker (current or former) and drinker (current or former) were 35.4\% (107) and $22.5 \%$ (68), respectively. The average age and BMI of the study population were $51 \pm 12$ years old and $23.9 \pm 3.8 \mathrm{~kg} / \mathrm{m}^{2}$, respectively. In total, 79 subjects were identified to have skin lesions, which characterized by skin pigmentation, depigmentation and/or hyperkerotosis. Urinary As species and methylation indices of the study population were listed in Table 1. The mean concentrations of urinary iAs, MMA, DMA and tAs were 108.3, 84.4, 320.8, and $513.6 \mu \mathrm{g} / \mathrm{g}$ Cr, respectively. DMA was the major As species in urine, followed by iAs and MMA. The average proportion of DMA, iAs and MMA were $60.9 \%, 23.7 \%$ and $15.5 \%$, respectively. Other two As methylation indices, namely PMI and SMI, were 0.76 and 0.80 , respectively.

\subsection{Differences of Urinary Arsenic Species and Methylation Indices among Subgroups}

Table 2 presents the differences of urinary As species and methylation indices among subgroups of sex, age, BMI, smoking and drinking. Levels of DMA, tAs, DMA\% and SMI were significantly lower in males than in females, while iAs\% was significantly higher in males. No sex differences were observed in iAs, MMA, MMA\% and PMI. Except iAs, DMA\% and SMI, age significantly influenced 
other As profiles. There was no difference in As metabolites and methylation indices between subjects with higher BMI $\left(>25 \mathrm{~kg} / \mathrm{m}^{2}\right)$ and lower BMI $\left(\leq 25 \mathrm{~kg} / \mathrm{m}^{2}\right)$, as well as smokers and non-smokers. Compared with never drinking subjects, current or former drinking subjects had higher iAs\%. However, there were no differences in other As profiles between them.

Table 1. Urinary arsenic species and methylation indices of the study population $(n=302)$.

\begin{tabular}{cccc}
\hline \multirow{2}{*}{ Variables a $^{*}$ Study Population } & \multicolumn{2}{c}{ Study Population } \\
\cline { 3 - 4 } & & Without Skin Lesions $(\boldsymbol{n}=\mathbf{2 2 3})$ & With Skin Lesions $(\boldsymbol{n}=\mathbf{7 9})$ \\
\hline & & Arsenic species $(\mu \mathrm{g} / \mathrm{g} \mathrm{Cr})$ \\
iAs & $108.3 \pm 138.9$ & $95.9 \pm 83.7$ & $143.4 \pm 229.9$ \\
MMA & $84.4 \pm 65.1$ & $77.9 \pm 65.9$ & $103.0 \pm 59.5$ \\
DMA & $320.8 \pm 232.8$ & $314.2 \pm 243.0$ & $339.6 \pm 201.4$ \\
tAs & $513.6 \pm 362.2$ & $487.9 \pm 341.2$ & $586.0 \pm 409.7$ \\
\hline & & Arsenic methylation indices \\
iAs\% & $23.7 \pm 15.5$ & $23.9 \pm 16.6$ & $22.9 \pm 11.8$ \\
MMA\% & $15.5 \pm 6.7$ & $14.5 \pm 6.2$ & $18.2 \pm 7.2$ \\
DMA\% & $60.9 \pm 13.7$ & $61.6 \pm 13.9$ & $58.9 \pm 13.1$ \\
PMI & $0.76 \pm 0.15$ & $0.76 \pm 0.17$ & $0.77 \pm 0.12$ \\
SMI & $0.80 \pm 0.09$ & $0.81 \pm 0.07$ & $0.76 \pm 0.11$ \\
\hline
\end{tabular}

${ }^{\mathrm{a}}$ Values are mean \pm SD.

\subsection{Differences of Urinary Arsenic Species between Subjects with and without Skin Lesions}

Crude and adjusted means of the urinary As species in subjects with and without skin lesions are presented in Table 3. The crude values of iAs, MMA and tAs were significantly higher in subjects with skin lesions than those of subjects without skin lesions $(p<0.05)$. The difference of crude value of DMA was not significant $(p=0.128)$. The significant differences in iAs, MMA and tAs were strengthened by adjusting sex in Model 1 and a significant difference of DMA was newly observed between those two groups. After further adjustments for age and BMI (Model 2), the significant differences in iAs and MMA were attenuated, while differences in DMA and tAs observed in Model 1 were disappeared. Further adjustments of Model 2 for smoking and drinking, the significant differences in iAs and MMA were retained, while the differences in DMA and tAs were also disappeared.

\subsection{Differences of Urinary Arsenic Methylation Indices between Subjects with and without} Skin Lesions

Table 4 shows the differences of crude and adjusted means of the urinary As methylation indices between subjects with and without skin lesions. The crude values of MMA\% was significantly higher in subjects with skin lesions than those of subjects without skin lesions, while SMI was significantly lower in subjects with skin lesions. After adjusting sex in Model 1, the significant difference in MMA\% and SMI were attenuated ( $p=0.002$ and 0.006 , respectively). The significant differences in MMA\% and SMI were attenuated by further adjustments for age and BMI (Model 2). Further adjustments of Model 2 for smoking and drinking, the significant differences in MMA\% and SMI were little changed. No differences were observed in iAs\%, DMA\% and PMI between subjects with and without skin lesions before and after the adjustments. 
Table 2. Differences of urinary arsenic species and methylation indices between subgroups.

\begin{tabular}{|c|c|c|c|c|c|c|c|c|c|c|}
\hline Variables & $n$ & $\mathrm{iAs}(\mu \mathrm{g} / \mathrm{g} \mathrm{Cr})^{\mathrm{a}}$ & $\operatorname{MMA}(\mu \mathrm{g} / \mathrm{g} \mathrm{Cr})^{\mathrm{a}}$ & DMA $(\mu \mathrm{g} / \mathrm{g} \mathrm{Cr})^{\mathrm{a}}$ & tAs $(\mu \mathrm{g} / \mathrm{g} \mathrm{Cr})^{\mathrm{a}}$ & iAs\% $\%^{a}$ & MMA\% $^{a}$ & DMA \% $^{a}$ & PMI $^{\text {a }}$ & SMI $^{\mathrm{a}}$ \\
\hline \multicolumn{11}{|l|}{ Sex } \\
\hline Male & 120 & $98.4 \pm 80.8$ & $80.6 \pm 58.1$ & $266.2 \pm 191.7$ & $445.2 \pm 277.1$ & $25.5 \pm 15.5$ & $16.8 \pm 7.6$ & $57.7 \pm 14.0$ & $0.75 \pm 0.15$ & $0.78 \pm 0.11$ \\
\hline Female & 182 & $114.9 \pm 166.4$ & $87.0 \pm 69.4$ & $356.8 \pm 250.3$ & $558.7 \pm 403.2$ & $22.5 \pm 15.4$ & $14.6 \pm 5.8$ & $63.0 \pm 13.1$ & $0.78 \pm 0.15$ & $0.81 \pm 0.07$ \\
\hline$p$-value & & 0.425 & 0.578 & 0.006 & 0.029 & 0.042 & 0.183 & 0.039 & 0.455 & 0.039 \\
\hline \multicolumn{11}{|l|}{ Age (years) ${ }^{b}$} \\
\hline$\leq 51$ & 155 & $118.8 \pm 180.8$ & $72.4 \pm 62.5$ & $277.5 \pm 210.8$ & $468.7 \pm 376.5$ & $27.2 \pm 17.7$ & $14.3 \pm 6.6$ & $58.5 \pm 14.5$ & $0.73 \pm 0.18$ & $0.81 \pm 0.08$ \\
\hline$>51$ & 147 & $97.3 \pm 71.3$ & $97.2 \pm 65.7$ & $366.5 \pm 246.4$ & $560.9 \pm 341.5$ & $19.9 \pm 11.7$ & $16.7 \pm 6.5$ & $63.5 \pm 12.3$ & $0.80 \pm 0.12$ & $0.79 \pm 0.10$ \\
\hline$p$-value & & 0.657 & $<0.001$ & 0.003 & 0.010 & $<0.001$ & 0.001 & 0.054 & $<0.001$ & 0.145 \\
\hline \multicolumn{11}{|l|}{ BMI $\left(\mathrm{kg} / \mathrm{m}^{2}\right)$} \\
\hline$\leq 25$ & 213 & $105.1 \pm 86.2$ & $86.1 \pm 65.4$ & $312.2 \pm 210.6$ & $503.4 \pm 312.6$ & $23.6 \pm 14.9$ & $16.0 \pm 6.8$ & $60.5 \pm 13.3$ & $0.76 \pm 0.15$ & $0.79 \pm 0.09$ \\
\hline$>25$ & 89 & $116.1 \pm 219.2$ & $80.4 \pm 64.7$ & $341.5 \pm 278.9$ & $538.0 \pm 461.1$ & $23.8 \pm 16.9$ & $14.3 \pm 6.3$ & $61.9 \pm 14.5$ & $0.76 \pm 0.17$ & $0.82 \pm 0.07$ \\
\hline$p$-value & & 0.144 & 0.199 & 0.748 & 0.451 & 0.323 & 0.125 & 0.415 & 0.980 & 0.171 \\
\hline \multicolumn{11}{|l|}{ Smoking } \\
\hline Current or former & 107 & $96.5 \pm 76.1$ & $85.3 \pm 64.4$ & $296.8 \pm 200.5$ & $478.6 \pm 295.3$ & $23.0 \pm 14.7$ & $16.3 \pm 6.6$ & $60.7 \pm 12.8$ & $0.77 \pm 0.15$ & $0.79 \pm 0.08$ \\
\hline Never & 195 & $114.8 \pm 163.3$ & $84.0 \pm 65.7$ & $334.0 \pm 248.2$ & $532.7 \pm 393.6$ & $24.0 \pm 15.9$ & $15.0 \pm 6.7$ & $61.0 \pm 14.2$ & $0.76 \pm 0.16$ & $0.80 \pm 0.09$ \\
\hline$p$-value & & 0.466 & 0.742 & 0.777 & 0.575 & 0.823 & 0.253 & 0.671 & 0.573 & 0.957 \\
\hline \multicolumn{11}{|l|}{ Drinking } \\
\hline Current or former & 68 & $105.0 \pm 88.0$ & $78.7 \pm 65.3$ & $258.7 \pm 177.6$ & $442.4 \pm 274.0$ & $27.8 \pm 17.8$ & $15.9 \pm 7.0$ & $56.3 \pm 14.6$ & $0.72 \pm 0.18$ & $0.78 \pm 0.08$ \\
\hline Never & 234 & $109.3 \pm 150.7$ & $86.1 \pm 65.1$ & $338.9 \pm 243.9$ & $534.3 \pm 382.1$ & $22.5 \pm 14.6$ & $15.3 \pm 6.6$ & $62.2 \pm 13.1$ & $0.78 \pm 0.15$ & $0.80 \pm 0.09$ \\
\hline$p$-value & & 0.475 & 0.500 & 0.102 & 0.255 & 0.008 & 0.968 & 0.112 & 0.082 & 0.755 \\
\hline
\end{tabular}

${ }^{\mathrm{a}}$ Values are mean $\pm \mathrm{SD} ;{ }^{\mathrm{b}}$ Cut point is median value of this variable. 
Table 3. Differences of adjusted means of urinary arsenic species between subjects with and without skin lesions.

\begin{tabular}{|c|c|c|c|}
\hline \multirow{2}{*}{ Characteristics } & \multicolumn{2}{|c|}{ Study Population } & \multirow{2}{*}{$p$-value } \\
\hline & Without Skin Lesions $(n=223)$ & With Skin Lesions $(n=79)$ & \\
\hline \multicolumn{4}{|l|}{ iAs $(\mu \mathrm{g} / \mathrm{g} \mathrm{Cr})^{\mathrm{a}}$} \\
\hline Crude $^{b}$ & $69.7(62.4,78.0)$ & $99.3(78.7,114.6)$ & 0.006 \\
\hline Model $1^{\mathrm{c}}$ & $68.1(60.7,76.4)$ & $95.9(79.4,115.6)$ & 0.003 \\
\hline Model $2^{\mathrm{d}}$ & $68.2(60.7,76.7)$ & $96.4(79.1,117.5)$ & 0.005 \\
\hline Model $3^{\mathrm{e}}$ & $70.6(61.8,80.9)$ & $99.1(80.5,121.9)$ & 0.006 \\
\hline \multicolumn{4}{|l|}{$\operatorname{MMA}(\mu \mathrm{g} / \mathrm{g} \mathrm{Cr})^{\mathrm{a}}$} \\
\hline Crude $^{\mathrm{b}}$ & $41.7(34.7,50.1)$ & $79.1(58.1,107.7)$ & 0.001 \\
\hline Model $1^{\mathrm{c}}$ & $40.2(33.2,48.6)$ & $80.2(58.9,109.4)$ & $<0.001$ \\
\hline Model $2^{\mathrm{d}}$ & $42.5(35.0,51.5)$ & $68.7(49.8,95.06)$ & 0.015 \\
\hline Model $3^{\mathrm{e}}$ & $42.9(34.4,53.5)$ & $69.3(49.4,97.3)$ & 0.016 \\
\hline \multicolumn{4}{|l|}{$\operatorname{DMA}(\mu \mathrm{g} / \mathrm{g} \mathrm{Cr})^{\mathrm{a}}$} \\
\hline Crude $^{\mathrm{b}}$ & $208.9(182.0,239.9)$ & $257.0(204.2,324.3)$ & 0.128 \\
\hline Model $1^{\mathrm{c}}$ & $195.9(170.2,225.4)$ & $264.2(210.4,331.9)$ & 0.030 \\
\hline Model $2^{\mathrm{d}}$ & $202.3(175.4,233.4)$ & $238.8(187.9,303.4)$ & 0.261 \\
\hline Model $3^{\mathrm{e}}$ & $206.1(175.0,242.7)$ & $243.8(189.7,313.3)$ & 0.255 \\
\hline \multicolumn{4}{|l|}{ tAs $(\mu \mathrm{g} / \mathrm{g} \mathrm{Cr})^{\text {a }}$} \\
\hline Crude $^{b}$ & $355.6(317.7,399.0)$ & $466.7(385.5,564.9)$ & 0.017 \\
\hline Model $1^{\mathrm{c}}$ & $339.6(302.0,381.9)$ & $476.4(393.6,575.4)$ & 0.003 \\
\hline Model $2^{\mathrm{d}}$ & $348.3(309.0,392.6)$ & $440.6(361.4,538.3)$ & 0.054 \\
\hline Model $3^{\mathrm{e}}$ & $354.0(309.0,406.4)$ & $447.7(363.1,552.1)$ & 0.057 \\
\hline
\end{tabular}

${ }^{\mathrm{a}}$ Values are adjusted mean and $95 \%$ confidence interval $(95 \% \mathrm{CI}) ;{ }^{\mathrm{b}}$ Crude model; ${ }^{\mathrm{c}}$ Model 1 adjusted for sex. ${ }^{\mathrm{d}}$ Model 2 adjusted for variable in Model 1, age and BMI; ${ }^{\mathrm{e}}$ Model 3 adjusted for variables in Model 2, smoking and drinking.

Table 4. Differences of adjusted means of urinary arsenic methylation indices between subjects with and without skin lesions.

\begin{tabular}{|c|c|c|c|}
\hline \multirow{2}{*}{ Characteristics } & \multicolumn{2}{|c|}{ Study Population } & \multirow{2}{*}{$p$-value } \\
\hline & Without Skin Lesions $(n=223)$ & With Skin Lesions $(n=79)$ & \\
\hline \multicolumn{4}{|l|}{ iAs\% ${ }^{a}$} \\
\hline Crude $^{\mathrm{b}}$ & $19.6(18.1,21.2)$ & $20.4(17.8,23.3)$ & 0.632 \\
\hline Model $1^{\mathrm{c}}$ & $20.0(18.5,21.8)$ & $20.1(17.6,23.0)$ & 0.955 \\
\hline Model $2^{\mathrm{d}}$ & $19.6(18.0,21.2)$ & $21.9(19.1,25.1)$ & 0.190 \\
\hline Model $3^{\mathrm{e}}$ & $20.0(18.2,21.9)$ & $22.1(19.2,25.6)$ & 0.216 \\
\hline \multicolumn{4}{|l|}{ MMA $\%^{a}$} \\
\hline Crude $^{\mathrm{b}}$ & $11.7(10.5,13.1)$ & $16.9(14.1,20.3)$ & 0.001 \\
\hline Model $1^{\mathrm{c}}$ & $11.9(10.6,13.3)$ & $16.9(14.1,20.2)$ & 0.002 \\
\hline Model $2^{\mathrm{d}}$ & $12.2(10.9,13.7)$ & $15.6(12.9,18.9)$ & 0.037 \\
\hline Model $3^{\mathrm{e}}$ & $12.1(10.6,13.8)$ & $15.5(12.7,16.9)$ & 0.036 \\
\hline
\end{tabular}


Table 4. Cont.

\begin{tabular}{|c|c|c|c|}
\hline \multirow{2}{*}{ Characteristics } & \multicolumn{2}{|c|}{ Study Population } & \multirow{2}{*}{$p$-value } \\
\hline & Without Skin Lesions $(n=223)$ & With Skin Lesions $(n=79)$ & \\
\hline \multicolumn{4}{|l|}{ DMA $\%^{a}$} \\
\hline Crude $^{b}$ & $58.8(55.3,62.4)$ & $55.2(49.9,61.0)$ & 0.294 \\
\hline Model $1^{\mathrm{c}}$ & $57.7(54.3,61.4)$ & $55.6(50.2,61.4)$ & 0.525 \\
\hline Model $2^{\mathrm{d}}$ & $58.1(54.6,61.9)$ & $54.2(48.8,60.1)$ & 0.273 \\
\hline Model $3^{\mathrm{e}}$ & $58.2(54.2,62.5)$ & $54.5(48.8,60.8)$ & 0.304 \\
\hline \multicolumn{4}{|l|}{$\mathrm{PMI}^{\mathrm{a}}$} \\
\hline Crude $^{b}$ & $0.72(0.69,0.76)$ & $0.76(0.70,0.82)$ & 0.322 \\
\hline Model $1^{\mathrm{c}}$ & $0.72(0.68,0.76)$ & $0.76(0.70,0.83)$ & 0.241 \\
\hline Model $2^{d}$ & $0.73(0.69,0.77)$ & $0.74(0.68,0.80)$ & 0.803 \\
\hline Model $3^{\mathrm{e}}$ & $0.72(0.68,0.76)$ & $0.73(0.67,0.80)$ & 0.754 \\
\hline \multicolumn{4}{|l|}{$\mathrm{SMI}^{\mathrm{a}}$} \\
\hline Crude $^{b}$ & $0.81(0.78,0.84)$ & $0.73(0.69,0.77)$ & 0.001 \\
\hline Model $1^{\mathrm{c}}$ & $0.80(0.77,0.83)$ & $0.73(0.69,0.77)$ & 0.006 \\
\hline Model $2^{d}$ & $0.80(0.77,0.83)$ & $0.73(0.69,0.78)$ & 0.024 \\
\hline Model $3^{\mathrm{e}}$ & $0.81(0.78,0.84)$ & $0.74(0.70,0.79)$ & 0.025 \\
\hline
\end{tabular}

\section{Discussion}

In this study, we investigated urinary As metabolites and the methylation capacities between subjects with and without skin lesions in Inner Mongolia. We found that demographic characteristics such as sex, age, and drinking can affect As metabolism. The absolute values of iAs and MMA were significantly higher in subjects with skin lesions than in controls before and after adjustment for several covariates. MMA\% was significantly higher in subjects with skin lesions, whereas SMI was significantly higher in subjects without skin lesions. Although an adjustment for potential confounding variables attenuated the significant differences, the differences in MMA\% and SMI did not change much between the two groups. Our findings of higher iAs, MMA and MMA\% and lower SMI values in skin lesions group indicate that subjects with higher levels of more toxic metabolites and lower methylation capacity may prone to As-induced skin lesions, although the cross-sectional study can only provide weak evidence of causality.

Inorganic As from drinking water is the primary source of human exposure. After metabolizing in liver, As is excreted in the urine primarily through the kidneys in a mixture of inorganic, monomethylated, and dimethylated forms [26]. Urinary As concentration is a good biomarker for internal dose and is considered as the most reliable indicator of recent exposure to iAs [1]. Previous studies have indicated that the relative distribution of iAs, MMA and DMA in urine of most population groups seem to be constant and have on average of $10 \%-30 \%, 10 \%-20 \%$ and $60 \%-70 \%$, respectively [27]. In this study, high levels of As in urine indicated that inhabitants of those two villages are at risk of high As exposure. Our results showed that the average percentages of As metabolites (iAs, MMA and DMA) in urine were $23.66 \%, 15.46 \%$, and $60.89 \%$, respectively, which consistent with previously studies (Table 1). 
However, there are some exceptions. Indigenous people in northern Argentina excrete only a small percentage of MMA in urine [28,29], whereas people in Taiwan excrete $20 \%-30 \%$ on average of MMA in urine [30]. Although the ethnic difference in the distribution of urinary As metabolites is still unclear, recent studies have indicated that genetic polymorphisms may be responsible for a large part of the variation of As metabolism between different population groups [6,31].

In this study, urinary As metabolites were compared between different subgroups including sex, age, BMI, smoking and drinking (Table 2). Women had a greater urinary excretion of tAs and DMA than those of men. Our results showed that the percentages of urinary As metabolites varied widely between men and women. Men had a lower As methylation capacity than women, which is characterized by significantly lower DMA\% and SMI values and higher iAs\% value. This finding was in accordance with many other studies, which suggested that women had better As methylation capacity than that of men [32,33]. The sexual difference in As methylation capacity can be partly explained by the effect of estrogen, which can increase the synthesis of choline by up-regulate phosphatidylethanolamine methyltransferase [34,35]. The choline was then oxidized into betaine, which can donate its methyl group for the regeneration of methionine from homocysteine [36]. Efficient one-carbon metabolism required adequate supply of methyl group donors can facilitate As methylation and elimination [37]. Therefore, it is reasonable to observe a better methylation capacity in women.

In this study, adult inhabitants older than 18 years were recruited, since most epidemiologic studies have agreed with a better methylation capacity in children [24,38]. Our results showed that older people had higher As excretion in urine than younger people. Except DMA\% and SMI, age significantly influenced other percentages of As metabolites (iAs\% and MMA\%) and the methylation index (PMI). This indicated that age may play a role in As metabolism. Studies in Taiwan have suggested that increasing MMA\% and decreasing DMA\% and SMI were associated with increasing age [39,40]. Similarly in a recent study carried out in Argentina, although there were no statistically significant difference in MMA\%, DMA\% and SMI among different age groups, aging was associated with a significantly decreasing iAs\% in urine [41]. In our study, the lower iAs\% as well as higher MMA\% and PMI in older group indicated that As methylation is incomplete among older persons, especially the second methylation capacity. Although the age effect on the As methylation capacity needs to be further confirmed, it was most likely explained by some confounding factors. Firstly, age is a possible surrogate for the duration of residence, which is an indicator of cumulative As exposure. Secondly, older age is probably associated with various functional changes in the organs involved in As metabolism.

BMI is a measure for indicating obesity or nutritional status, which may have an effect on As metabolism. Studies in Taiwan revealed that BMI was positively associated with DMA\% and negatively associated with MMA\% and tAs [40,42]. In the study by evaluating the association between BMI and As methylation efficiency, higher BMI was found to be associated with low MMA\% or high SMI [43]. However, in this study, BMI was found to be not associated with any of the urinary As species or methylation indices. The effect of smoking on As metabolism is inconsistent. Some studies suggested that smoking is associated with a poorer methylation capacity [19,39]. However, some other studies suggested that smoking is not associated with As methylation capacity [41]. Our results showed that smoking was not associated with any of the urinary As metabolites or methylation indices. Additionally, we found that non-drinkers have lower iAs\% than that of drinkers. This is in accordance 
with the findings of Hopenhayn-Rich et al. [44], which suggested that alcohol drinkers had a higher iAs\%. However, the alcohol effects on As methylation cannot be confirmed in studies performed in Taiwan [39]. Therefore, more research works are required to provide evidence that drinking could exert an effect on As metabolism.

The mechanisms of As toxicity are not fully elucidated. Methylation of iAs has been previously thought to be a detoxification pathway. However, recent studies have confirmed that trivalent intermediates, such as $\mathrm{MMA}^{\mathrm{III}}$ and $\mathrm{DMA}^{\mathrm{III}}$, are produced during As metabolism and are more toxic than other metabolites [45,46]. It has been demonstrated that urinary As profile is correlated well for plenty of chronic effects related to As concentrations in drinking water [7]. Analyses of the urinary As profile can give a hint to the methylation capacity of exposed individuals. In this study, no significant difference were found in tAs excretion between subjects with and without skin lesions, which indicating similar As exposure among the study population. Although urinary DMA were similar in the two groups, we found that subjects with skin lesions had a higher urinary iAs and MMA than subjects without skin lesions by adjustment for several potential confounders (Table 3). Our results suggested that an individual susceptible to As-induced skin lesions may excrete more toxic metabolites than the controls under the same As exposure level. It was shown that cases with skin lesions had a higher urinary MMA\% and lower SMI than controls by adjustment for sex, age, BMI, smoking and drinking (Table 4). This indicated that cases with skin lesions have a lower methylation capacity, especially the secondary methylation step. Several studies conducted in Taiwan, Mexico and Bangladesh have found that higher percentage of MMA was associated with a higher risk of skin lesions $[13,15,47,48]$. In this study, we were unable to determine $\mathrm{MMA}^{\mathrm{III}}$ directly. Therefore, urinary MMA was used to be a marker of MMA ${ }^{\mathrm{III}}$ in human body. Although the degree to which urinary MMA may be an accurate surrogate for $\mathrm{MMA}^{\mathrm{III}}$ level is unclear, the confirmed highly toxic of MMA ${ }^{\mathrm{III}}$ supports our findings that higher MMA is associated with As-induced skin lesions.

\section{Conclusions}

In summary, the present study suggested that As metabolism can be influenced by demographic characteristics such as sex, age, BMI and drinking. Subjects with skin lesions had a lower As methylation capability than subjects without skin lesions, which characterized by higher urinary excretion of toxic iAs and MMA, as well as higher MMA\% and lower SMI values.

\section{Acknowledgments}

The authors would like to thank the villagers for participating in this study. This work was supported by National Natural Science Foundation of China (No. 81302390) and by Specialized Research Fund for the Doctoral Program of Higher Education (No. 20131202120020) and by China Postdoctoral Science Foundation (No. 2014M551034).

\section{Author Contributions}

Qiang Zhang carried out the study and drafted the paper. Yongfang Li and Juan Liu assisted the data analysis and managed the manuscript. Da Wang and Quanmei Zheng assisted the first author 
building the research framework and carried out the study. Guifan Sun designed and took charge of the whole framework of this work.

\section{Conflicts of Interest}

The authors declare no conflict of interest.

\section{References}

1. Marchiset-Ferlay, N.; Savanovitch, C.; Sauvant-Rochat, M.P. What is the best biomarker to assess arsenic exposure via drinking water? Environ. Int. 2012, 39, 150-171.

2. Rodríguez-Lado, L.; Sun, G.; Berg, M.; Zhang, Q.; Xue, H.; Zheng, Q.; Johnson, C.A. Groundwater arsenic contamination throughout China. Science 2013, 341, 866-868.

3. Argos, M.; Kalra, T.; Pierce, B.L.; Chen, Y.; Parvez, F.; Islam, T.; Ahmed, A.; Hasan, R.; Hasan, K.; Sarwar, G.; et al. A prospective study of arsenic exposure from drinking water and incidence of skin lesions in Bangladesh. Am. J. Epidemiol. 2011, 174, 185-194.

4. Guo, X.; Fujino, Y.; Ye, X.; Liu, J.; Yoshimura, T. Japan Inner Mongolia Arsenic Pollution Study Group. Association between multi-level inorganic arsenic exposure from drinking water and skin lesions in China. Int. J. Environ. Res. Public Health 2006, 3, 262-267.

5. Chen, Y.; Wu, F.; Liu, M.; Parvez, F.; Slavkovich, V.; Eunus, M.; Ahmed, A.; Argos, M.; Islam, T.; Rakibuz-Zaman, M.; et al. A prospective study of arsenic exposure, arsenic methylation capacity, and risk of cardiovascular disease in Bangladesh. Environ. Health Perspect. 2013, 121, 832-838.

6. Fu, S.; Wu, J.; Li, Y.; Liu, Y.; Gao, Y.; Yao, F.; Qiu, C.; Song, L.; Wu, Y.; Liao, Y.; et al. Urinary arsenic metabolism in a Western Chinese population exposed to high-dose inorganic arsenic in drinking water: Influence of ethnicity and genetic polymorphisms. Toxicol. Appl. Pharmacol. 2014, 274, 117-123.

7. Tseng, C.H. Arsenic methylation, urinary arsenic metabolites and human diseases: Current perspective. J. Environ. Sci. Health C Environ. Carcinog. Ecotoxicol. Rev. 2007, 25, 1-22.

8. Aposhian, H.V.; Aposhian, M.M. Arsenic toxicology: Five questions. Chem. Res. Toxicol. 2006, 19, 1-15.

9. Hayakawa, T.; Kobayashi, Y.; Cui, X.; Hirano, S. A new metabolic pathway of arsenite: Arsenic-glutathione complexes are substrates for human arsenic methyltransferase Cyt19. Arch. Toxicol. 2005, 79, 183-191.

10. Hughes, M.F.; Beck, B.D.; Chen, Y.; Lewis, A.S.; Thomas, D.J. Arsenic exposure and toxicology: A historical perspective. Toxicol. Sci. 2011, 123, 305-332.

11. Petrick, J.S.; Ayala-Fierro, F.; Cullen, W.R.; Carter, D.E.; Aposhian, H.V. Monomethylarsonous acid (MMA(III)) is more toxic than arsenite in Chang human hepatocytes. Toxicol. Appl. Pharmacol. 2000, 163, 203-207.

12. Huang, Y.K.; Tseng, C.H.; Huang, Y.L.; Yang, M.H.; Chen, C.J.; Hsueh, Y.M. Arsenic methylation capability and hypertension risk in subjects living in arseniasis-hyperendemic areas in southwestern Taiwan. Toxicol. Appl. Pharmacol. 2007, 218, 135-142. 
13. Li, X.; Li, B.; Xu, Y.; Wang, Y.; Jin, Y.; Itoh, T.; Yoshida, T.; Sun, G. Arsenic methylation capacity and its correlation with skin lesions induced by contaminated drinking water consumption in residents of chronic arsenicosis area. Environ. Toxicol. 2011, 26, 118-123.

14. Melak, D.; Ferreccio, C.; Kalman, D.; Parra, R.; Acevedo, J.; Pérez, L.; Cortés, S.; Smith, A.H.; Yuan, Y.; Liaw, J.; et al. Arsenic methylation and lung and bladder cancer in a case-control study in northern Chile. Toxicol. Appl. Pharmacol. 2014, 274, 225-231.

15. Yu, R.C.; Hsu, K.H.; Chen, C.J.; Froines, J.R. Arsenic methylation capacity and skin cancer. Cancer Epidemiol. Biomarkers Prev. 2000, 9, 1259-1262.

16. Agusa, T.; Iwata, H.; Fujihara, J.; Kunito, T.; Takeshita, H.; Minh, T.B.; Trang, P.T.; Viet, P.H.; Tanabe, S. Genetic polymorphisms in AS3MT and arsenic metabolism in residents of the Red River Delta, Vietnam. Toxicol. Appl. Pharmacol. 2009, 236, 131-141.

17. Engström, K.S.; Nermell, B.; Concha, G.; Strömberg, U.; Vahter, M.; Broberg, K. Arsenic metabolism is influenced by polymorphisms in genes involved in one-carbon metabolism and reduction reactions. Mutat. Res. 2009, 667, 4-14.

18. Gribble, M.O.; Crainiceanu, C.M.; Howard, B.V.; Umans, J.G.; Francesconi, K.A.; Goessler, W.; Zhang, Y.; Silbergeld, E.K.; Guallar, E.; Navas-Acien, A. Body composition and arsenic metabolism: A cross-sectional analysis in the Strong Heart Study. Environ. Health 2013, 12, 107.

19. Lindberg, A.L.; Sohel, N.; Rahman, M.; Persson, L.A.; Vahter, M. Impact of smoking and chewing tobacco on arsenic-induced skin lesions. Environ. Health Perspect. 2010, 118, 533-538.

20. Tseng, C.H. A review on environmental factors regulating arsenic methylation in humans. Toxicol. Appl. Pharmacol. 2009, 235, 338-350.

21. Smedley, P.L.; Zhang, M.; Zhang, G.; Luo, Z. Mobilisation of arsenic and other trace elements in fluviolacustrine aquifers of the Huhhot Basin, Inner Mongolia. Appl. Geochem. 2003, 18, 1453-1477.

22. Sun, G. Arsenic contamination and arsenicosis in China. Toxicol. Appl. Pharmacol. 2004, 198, 268-271.

23. Lu, C.; Zhao, F.; Sun, D.; Zhong, Y.; Yu, X.; Li, G.; Lv, X.; Sun, G.; Jin, Y. Comparison of speciated arsenic levels in the liver and brain of mice between arsenate and arsenite exposure at the early life. Environ. Toxicol. 2014, 29, 797-803.

24. Sun, G.; Xu, Y.; Li, X.; Jin, Y.; Li, B.; Sun, X. Urinary arsenic metabolites in children and adults exposed to arsenic in drinking water in Inner Mongolia, China. Environ. Health Perspect. 2007, $115,648-652$.

25. Zhang, Q.; Wang, D.; Zheng, Q.; Zheng, Y.; Wang, H.; Xu, Y.; Li, X.; Sun, G. Joint effects of urinary arsenic methylation capacity with potential modifiers on arsenicosis: A cross-sectional study from an endemic arsenism area in Huhhot Basin, northern China. Environ. Res. 2014, 132, 281-289.

26. Vahter, M. Mechanisms of arsenic biotransformation. Toxicology 2002, 181-182, 211-217.

27. Vahter, M. Genetic polymorphism in the biotransformation of inorganic arsenic and its role in toxicity. Toxicol. Lett. 2000, 112-113, 209-217.

28. Concha, G.; Nermell, B.; Vahter, M.V. Metabolism of inorganic arsenic in children with chronic high arsenic exposure in northern Argentina. Environ. Health Perspect. 1998, 106, 355-359.

29. Vahter, M.; Concha, G.; Nermell, B.; Nilsson, R.; Dulout, F.; Natarajan, A.T. A unique metabolism of inorganic arsenic in native Andean women. Eur. J. Pharmacol. 1995, 293, 455-462. 
30. Hsueh, Y.M.; Huang, Y.L.; Huang, C.C.; Wu, W.L.; Chen, H.M.; Yang, M.H.; Lue, L.C.; Chen, C.J. Urinary levels of inorganic and organic arsenic metabolites among residents in an arseniasis-hyperendemic area in Taiwan. J. Toxicol. Environ. Health A 1998, 54, 431-444.

31. Engström, K.; Vahter, M.; Mlakar, S.J.; Concha, G.; Nermell, B.; Raqib, R.; Cardozo, A.; Broberg, K. Polymorphisms in arsenic(+III oxidation state) methyltransferase (AS3MT) predict gene expression of AS3MT as well as arsenic metabolism. Environ. Health Perspect. 2011, 119, $182-188$.

32. Lindberg, A.L.; Rahman, M.; Persson, L.A.; Vahter, M. The risk of arsenic induced skin lesions in Bangladeshi men and women is affected by arsenic metabolism and the age at first exposure. Toxicol. Appl. Pharmacol. 2008, 230, 9-16.

33. Tseng, C.H. Blackfoot disease and arsenic: A never-ending story. J. Environ. Sci. Health C 2005, $23,55-74$.

34. Fischer, L.M.; daCosta, K.A.; Kwock, L.; Stewart, P.W.; Lu, T.S.; Stabler, S.P.; Allen, R.H.; Zeisel, S.H. Sex and menopausal status influence human dietary requirements for the nutrient choline. Am. J. Clin. Nutr. 2007, 85, 1275-1285.

35. Vahter, M.E. Interactions between arsenic-induced toxicity and nutrition in early life. J. Nutr. 2007, 137, 2798-2804.

36. Chiuve, S.E.; Giovannucci, E.L.; Hankinson, S.E.; Zeisel, S.H.; Dougherty, L.W.; Willett, W.C.; Rimm, E.B. The association between betaine and choline intakes and the plasma concentrations of homocysteine in women. Am. J. Clin. Nutr. 2007, 86, 1073-1081.

37. Hall, M.N.; Gamble, M.V. Nutritional manipulation of one-carbon metabolism: Effects on arsenic methylation and toxicity. J. Toxicol. 2012, 2012, doi:10.1155/2012/595307.

38. Chowdhury, U.K.; Rahman, M.M.; Sengupta, M.K.; Lodh, D.; Chanda, C.R.; Roy, S.; Quamruzzaman, Q.; Tokunaga, H.; Ando, M.; Chakraborti, D. Pattern of excretion of arsenic compounds [arsenite, arsenate, MMA(V), DMA(V)] in urine of children compared to adults from an arsenic exposed area in Bangladesh. J. Environ. Sci. Heal. A Tox. Hazard. Subst. Environ. Eng. 2003, 38, 87-113.

39. Huang, Y.K.; Huang, Y.L.; Hsueh, Y.M.; Yang, M.H.; Wu, M.M.; Chen, S.Y.; Hsu, L.I.; Chen, C.J. Arsenic exposure, urinary arsenic speciation, and the incidence of urothelial carcinoma: A twelve-year follow-up study. Cancer Causes Control 2008, 19, 829-839.

40. Tseng, C.H.; Huang, Y.K.; Huang, Y.L.; Chung, C.J.; Yang, M.H.; Chen, C.J.; Hsueh, Y.M. Arsenic exposure, urinary arsenic speciation, and peripheral vascular disease in blackfoot disease-hyperendemic villages in Taiwan. Toxicol. Appl. Pharmacol. 2005, 206, 299-308.

41. Steinmaus, C.; Moore, L.E.; Shipp, M.; Kalman, D.; Rey, O.A.; Biggs, M.L.; Hopenhayn, C.; Bates, M.N.; Zheng, S.; Wiencke, J.K.; et al. Genetic polymorphisms in MTHFR 677 and 1298, GSTM1 and T1, and metabolism of arsenic. J. Toxicol. Environ. Health A 2007, 70, 159-170.

42. Su, C.T.; Lin, H.C.; Choy, C.S.; Huang, Y.K.; Huang, S.R.; Hsueh, Y.M. The relationship between obesity, insulin and arsenic methylation capability in Taiwan adolescents. Sci. Total Environ. 2012, 414, 152-158.

43. Gomez-Rubio, P.; Roberge, J.; Arendell, L.; Harris, R.B.; O’Rourke, M.K.; Chen, Z.; Cantu-Soto, E.; Meza-Montenegro, M.M.; Billheimer, D.; Lu, Z.; et al. Association between body 
mass index and arsenic methylation efficiency in adult women from southwest U.S. and northwest Mexico. Toxicol. Appl. Pharmacol. 2011, 252, 176-182.

44. Hopenhayn-Rich, C.; Biggs, M.L.; Smith, A.H.; Kalman, D.A.; Moore, L.E. Methylation study of a population environmentally exposed to arsenic in drinking water. Environ. Health Perspect. 1996, 104, 620-628.

45. Stýblo, M.; Drobná, Z.; Jaspers, I.; Lin, S.; Thomas, D.J. The role of biomethylation in toxicity and carcinogenicity of arsenic: A research update. Environ. Health Perspect. 2002, 110, 767-771.

46. Thomas, D.J.; Styblo, M.; Lin, S. The cellular metabolism and systemic toxicity of arsenic. Toxicol. Appl. Pharmacol. 2001, 176, 127-144.

47. Ahsan, H.; Chen, Y.; Kibriya, M.G.; Slavkovich, V.; Parvez, F.; Jasmine, F.; Gamble, M.V.; Graziano, J.H. Arsenic metabolism, genetic susceptibility, and risk of premalignant skin lesions in Bangladesh. Cancer Epidemiol. Biomarkers Prev. 2007, 16, 1270-1278.

48. Del Razo, L.M.; García-Vargas, G.G.; Vargas, H.; Albores, A.; Gonsebatt, M.E.; Montero, R.; Ostrosky-Wegman, P.; Kelsh, M.; Cebrián, M.E. Altered profile of urinary arsenic metabolites in adults with chronic arsenicism. A pilot study. Arch. Toxicol. 1997, 71, 211-217.

(C) 2014 by the authors; licensee MDPI, Basel, Switzerland. This article is an open access article distributed under the terms and conditions of the Creative Commons Attribution license (http://creativecommons.org/licenses/by/3.0/). 